\title{
Radar signatures of road vehicles: airborne SAR experiments
}

\author{
G. Palubinskas, H. Runge, P. Reinartz \\ DLR German Aerospace Center, Remote Sensing Technology Institute \\ Oberpfaffenhofen, 82234 Wessling, Germany \\ Gintautas.Palubinskas@dlr.de
}

\begin{abstract}
The German radar satellite TerraSAR-X is a high resolution, dual receive antenna SAR satellite, which will be launched in spring 2006. Since it will have the capability to measure the velocity of moving targets, the acquired interferometric data can be useful for traffic monitoring applications on a global scale.

DLR has started already the development of an automatic and operational processing system which will detect cars, measure their speed and assign them to a road. Statistical approaches are used to derive the vehicle detection algorithm, which require the knowledge of the radar signatures of vehicles, especially under consideration of the geometry of the radar look direction and the vehicle orientation. Simulation of radar signatures is a very difficult task due to the lack of realistic models of vehicles.

In this paper the radar signatures of the parking cars are presented. They are estimated experimentally from airborne ESAR X-band data, which have been collected during flight campaigns in 2003-2005. Several test cars of the same type placed in carefully selected orientation angles and several over-flights with different heading angles made it possible to cover the whole range of aspect angles from $0^{\circ}$ to $180^{\circ}$. The large synthetic aperture length or beam width angle of $7^{\circ}$ can be divided into several looks. Thus processing of each look separately allows to increase the angle resolution. Such a radar signature profile of one type of vehicle over the whole range of aspect angles in fine resolution can be used further for the verification of simulation studies and for the performance prediction for traffic monitoring with TerraSAR-X.
\end{abstract}

Keywords: Radar cross section, parking cars, airborne E-SAR sensor, look processing

\section{INTRODUCTION}

The German radar satellite TerraSAR-X is a high resolution, dual receive antenna (DRA) SAR satellite, which will be launched in spring 2006 (Buckreuss ${ }^{1}$, Mittermayer ${ }^{2}$ ). Since it will have the capability to measure the velocity of moving targets (DRA mode), the acquired interferometric data can be useful for traffic monitoring applications on a global scale. DLR has started already the development of a processing system (called "traffic processor") which will detect cars, measure their speed and assign them to a road (Runge ${ }^{3,4}$, Meyer ${ }^{5}$, Suchandt ${ }^{6,7}$ ). For the implementation of the vehicle detection algorithms the knowledge of the radar signatures of a vehicle is of great importance, especially under consideration of the geometry of the radar look direction and the vehicle orientation. The radar cross section (RCS) for various military targets is well known, but for civilian road vehicles, this information is still missing or insufficient.

For the development and testing of the processing algorithms three airborne SAR flight campaigns have been conducted with DLR's Experimental SAR Sensor E-SAR. SAR data have been collected in various frequencies (X, C and L) and polarizations. In parallel to the SAR measurements, very high resolution (up to $0.2 \mathrm{~m}$ ) optical data have been acquired, used to accomplish the detection of vehicles in the lower resolution radar images and, additionally, to measure the vehicle orientation (aspect angle). Test cars have been placed in the empty parking lots. The statistical analysis is performed for various types of cars dependent on the aspect and incidence angles. Further flight campaigns and simulation studies are planned in order to cover the full range of aspect and incidence angles.

The paper provides an overview of the results of the investigations and shows examples of radar signatures of road cars.

\section{THEORY}

The aim is to estimate the radar cross section (RCS) of a car from a single look slant range complex SAR image (SLC). The value of RCS depends on radar parameters: frequency $(f)$, polarization $(p)$; car parameters: type, shape, material and 
especially geometry parameters: incidence angle and car aspect angle. For the definition of angles see Fig. 1. Thus the $\mathrm{RCS}$ of a car is a function of a lot of parameters $\sigma(f, p, \theta, \alpha, c a r)$.

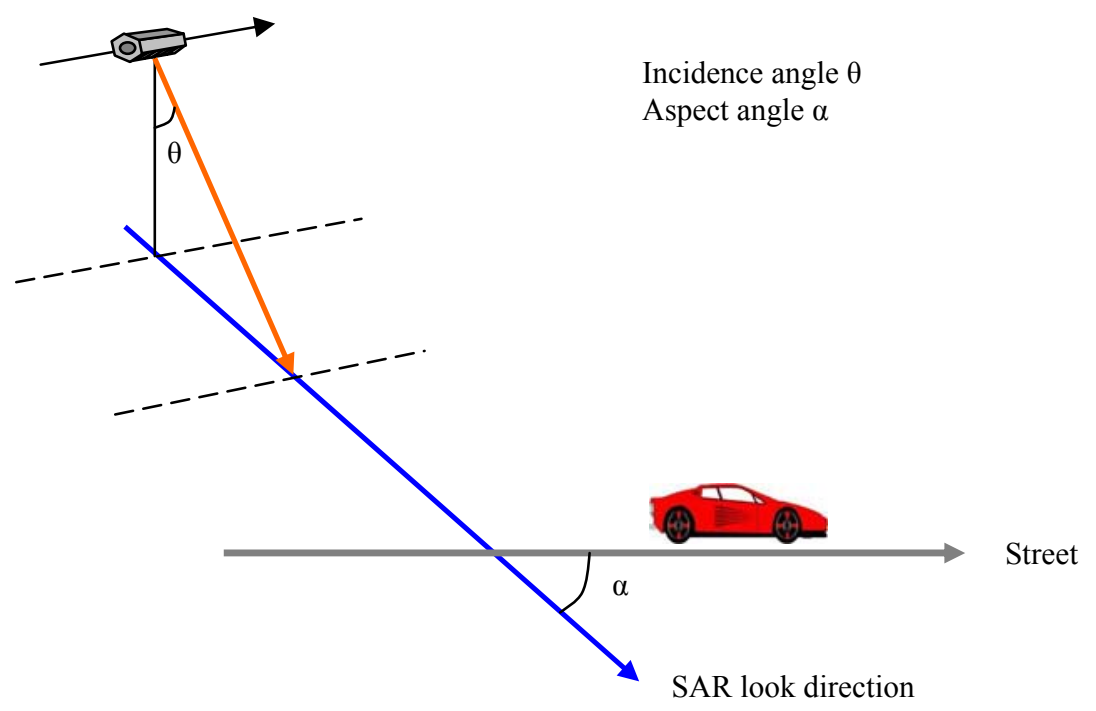

Figure 1: Definition of incidence and aspect angles.

Radar cross section for a target is defined as $\left(\right.$ Raney $^{8},{ }^{9}$, Bamler $\left.^{10}\right)$

$$
\sigma\left(m^{2}\right)=\frac{1}{K} \int_{-\infty}^{\infty} \int_{-\infty}^{\infty} I_{\sigma}(x, y) \cdot d x \cdot d y \approx \frac{1}{K} \cdot \Delta x \cdot \Delta y \cdot \sum_{k, l} I_{\sigma}(k, l)
$$

where $K$ is a scaling factor, $\Delta x \cdot \Delta y$ - pixel area in slant range and $\sum_{k, l} I_{\sigma}(k, l)$ - integrated power of a scatter (radar brightness or beta values). We can rewrite the formula in $d B$

$$
\sigma\left(d B m^{2}\right)=-10 \cdot \log K+10 \cdot \log (\Delta x \cdot \Delta y)+10 \cdot \log \sum_{k, l} I_{\sigma}(k, l),
$$

where the first term is a calibration scale factor, $\Delta x$ - azimuth pixel spacing, $\Delta y$ - slant range pixel spacing and the last term is measured in SLC image with DLR's Image Analysis Software - IAS.

RCS can be estimated in two different ways: simulated, if geometrical models of cars are available or measured experimentally from SAR image data. In this paper we consider the experimental way.

\section{SENSORS}

DLR's airborne experimental SAR sensor ESAR was used in the flight campaigns for the acquisition of the radar image data. This system has been in use for different applications and has been continuously improved and extended over a period of more than 16 years by now. It is operated on a Do-228 aircraft. Detailed description of the sensor can be found in Scheiber ${ }^{11}$. Table 1 lists the main ESAR system parameters for the SAR experiments. Detailed description on the flight campaigns is given in the experimental part of the paper.

To locate vehicles in the radar images and to verify the measurements, optical reference data were recorded simultaneously with the SAR acquisition. The sensor platform additionally carried an optical RMK-A camera (sampling rate $1 / 3 \mathrm{~Hz}$ ) during the first two campaigns and a digital camera (CANON, $8 \mathrm{M}$ pixel) during the last campaign, which took images at a sampling rate of about $3 \mathrm{~Hz}$. These were processed to a resolution of $0.5 \mathrm{~m}$ and car positions and 
velocities were interactively extracted from sequences of images. The accuracy of these data was $2 \mathrm{~m}$ for the $\mathrm{x}, \mathrm{y}-$ coordinates and about $5 \mathrm{~km} / \mathrm{h}$ for the velocities. Details on the processing of the optical data can be found in Reinartz ${ }^{12}$.

Table 1: ESAR system parameters.

\begin{tabular}{|l|c|}
\hline Parameter & Value \\
\hline frequency band & $\mathrm{X}(9.6 \mathrm{GHz})$ \\
\hline polarization & $\mathrm{HH} / \mathrm{VV}$ \\
\hline wavelength & $0.311 \mathrm{~m}$ \\
\hline range bandwidth & $100 \mathrm{MHz}$ \\
\hline pulse repetition frequency & $1000 / 2000 \mathrm{~Hz}$ \\
\hline azimuth processing bandwidth & $52 / 1000 \mathrm{~Hz}$ \\
\hline sensor forward velocity & $88 \mathrm{~m} / \mathrm{s}$ \\
\hline altitude above ground & $3940 \mathrm{~m}$ \\
\hline incidence angle & $20-60 \mathrm{deg}$ \\
\hline resolution (rg x az) & $2 \mathrm{~m} \times 0.085 \mathrm{~m}$ \\
\hline SLC pixel spacing (rg x az) & $1.50 \mathrm{~m} \times 0.089 \mathrm{~m}$ \\
\hline
\end{tabular}

\section{LOOK PROCESSING}

The large synthetic aperture length or beam width angle of approximately $7^{\circ}$ of the airborne radar sensor can be divided into several looks, thus decreasing the target's illumination time and increasing the aspect angle resolution. The concept of such look processing into seven looks is illustrated in Fig. 2.

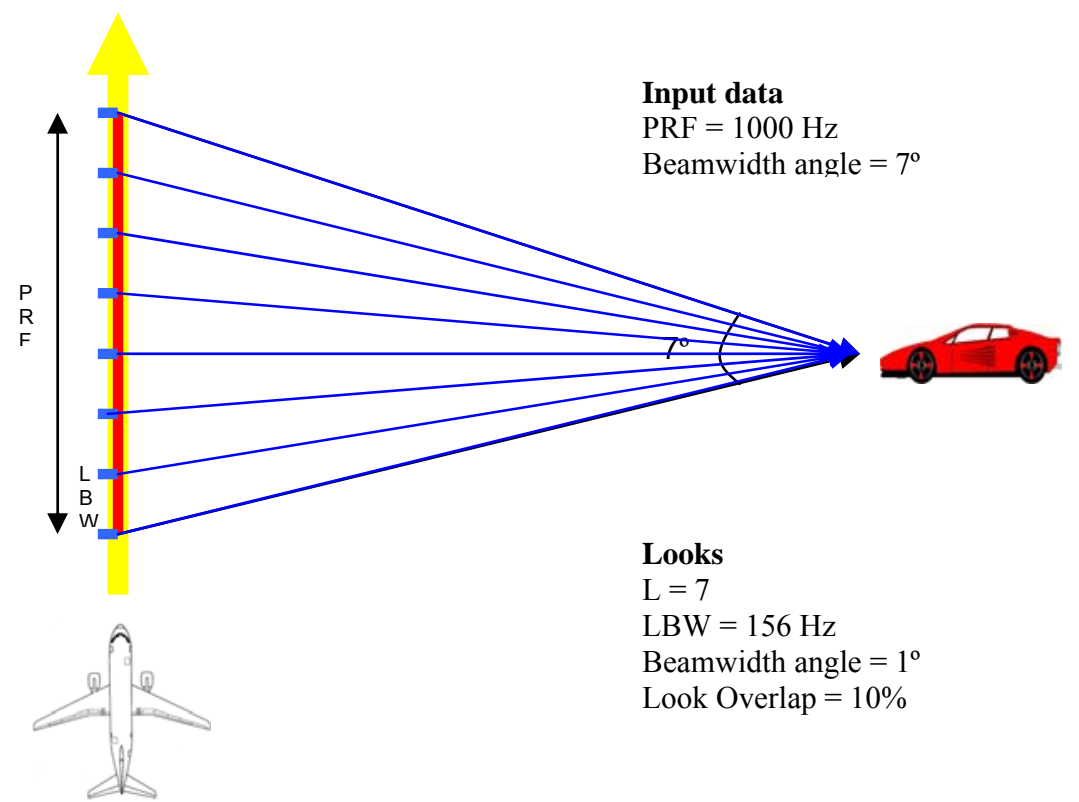

Figure 2: Concept for look processing.

In the subsequent experiments the following setup was used. The whole bandwidth of $1000 \mathrm{~Hz}$ in azimuth was divided into $L=21$ looks, with the look bandwidth $L B W=52 \mathrm{~Hz}$ for each look and with look overlap of approximately $10 \%$. It resulted in the beamwidth angle of $0.3^{\circ}$, similar to that of TerraSAR-X. 


\section{EXPERIMENTS}

The experimental data have been collected by DLR airborne E-SAR sensor during the three flight campaigns in Germany: first, on May 8th, 2003 over the cities of Mannheim and Ludwigshafen, second, on April $20^{\text {th }}, 2004$ over Oberpfaffenhofen and, third, on May $12^{\text {th }}, 2005$ over Gilching. These campaigns exhibited different radar and optical data acquisition modes and test cars configurations. Therefore they are treated separately in the following sections.

\subsection{Mannheim flight campaign}

During this flight campaign the polarimetric SAR data were collected for various frequencies and polarizations: $\mathrm{X}-\mathrm{HH}$, C-VH, C-VV, L-HH, L-HV and L-VV. Preliminary results were presented in Palubinskas ${ }^{13}$. The footprint of a SAR data take with $\mathrm{X}-\mathrm{HH}$ is shown in Fig. 3.

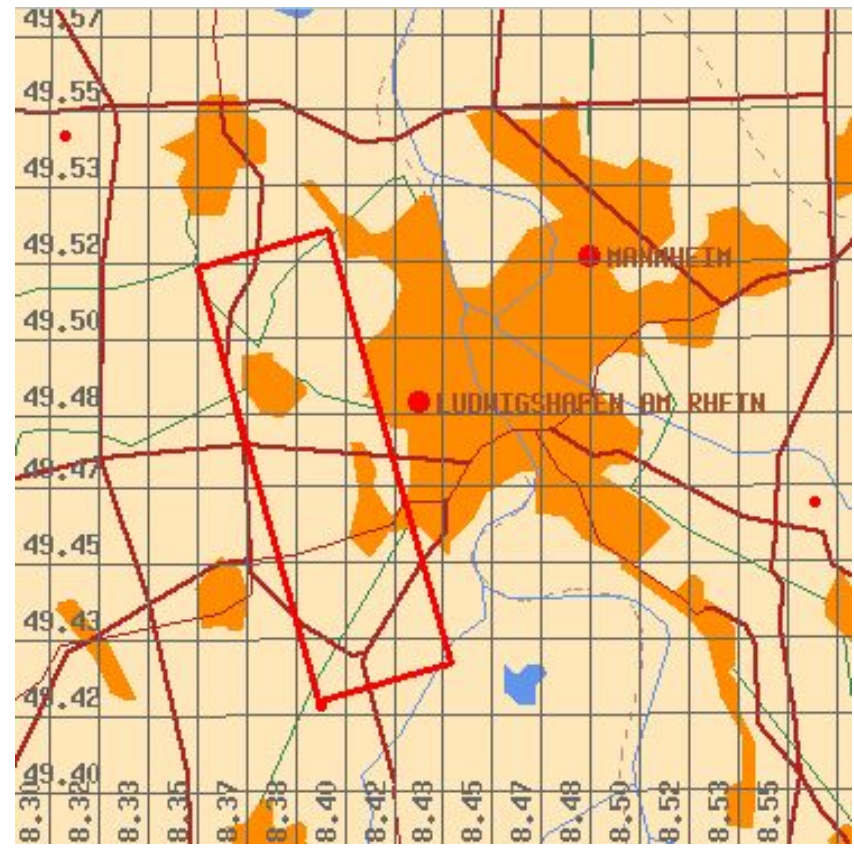

Figure 3: The footprint of SAR data take for Mannheim campaign.

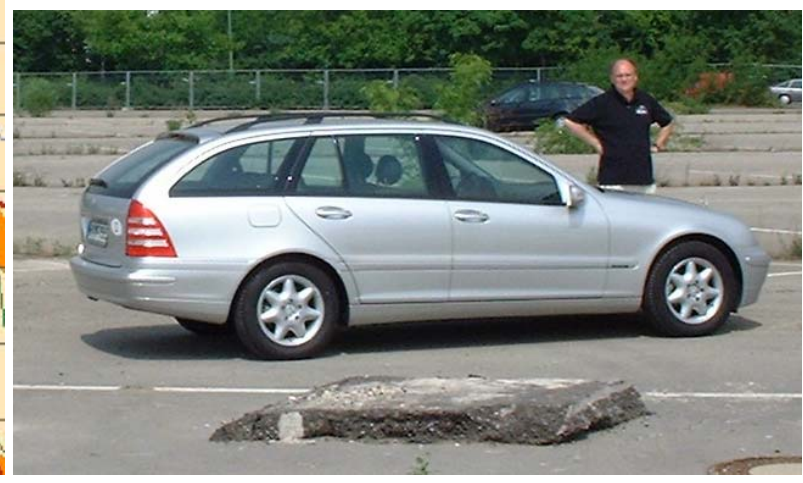

Figure 4: Test car used in the experiment.

In parallel to the SAR measurements, very high resolution (up to $0.2 \mathrm{~m}$ ) optical data were acquired with a ZEISS RMK large format camera on a second aircraft. They were used to accomplish the interactive detection of parking cars in radar images and, additionally, to measure the car orientation (aspect angle). Four test cars of the same type (Mercedes, Cclass, T-model, Fig. 4) were placed on an empty car parking lot for validation purposes. These four test cars were used to derive the RCS plot vs. aspect angle for X-HH (see Fig. 5). The incidence angle was approximately $\theta=42^{\circ}$. Aspect angle for rear view is $0^{\circ}$, side view $-90^{\circ}$ and front view $-180^{\circ}$. Only the small part, $4 \times 7=28^{\circ}$, of the whole aspect angle range $180^{\circ}$ is covered. Plots for each car are presented in Fig. 6-9. From Fig.5 we see, that RCS of cars M1, M2 ("good" angles) is between 0 to $12 \mathrm{~dB} \mathrm{~m}$, as for cars M3, M4 ("bad" angles) is around $0 \mathrm{~dB} \mathrm{~m}$, or more precisely between -3 and $6 \mathrm{~dB} \mathrm{~m}^{2}$. Figs. 6-9 show a great variation of RCS on the small changes of aspect angle, up to $8 \mathrm{~dB} \mathrm{~m}^{2}$ for $0.3^{\circ}$. A statistical test was used to check if the differences between the "good" and "bad" angles are significant. The Student's Tstatistic test or t-means test checks if two sample populations have significantly different means. The significance is the value in the interval $[0,1]$. A small value $(0.05$ or 0.01$)$ indicates that populations have significantly different means. The results for the four cars are summarized in the Table 2. Empty fields are due the symmetry. The significant RCS mean difference for $\{M 1, M 2\}$ in comparison to $\{M 3, M 4\}$ is confirmed statistically. 
Radar cross section of cars M1-4 (X-HH, $\theta=42^{\circ}$, Mannheim2003)

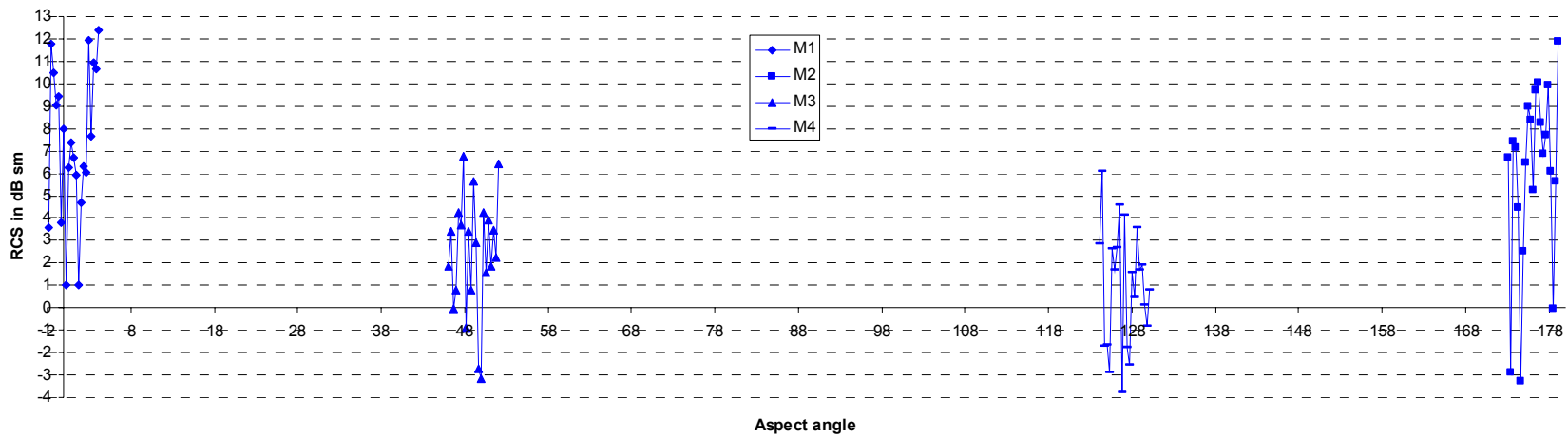

Figure 5: RCS plot vs. aspect angle for M1-4 cars.

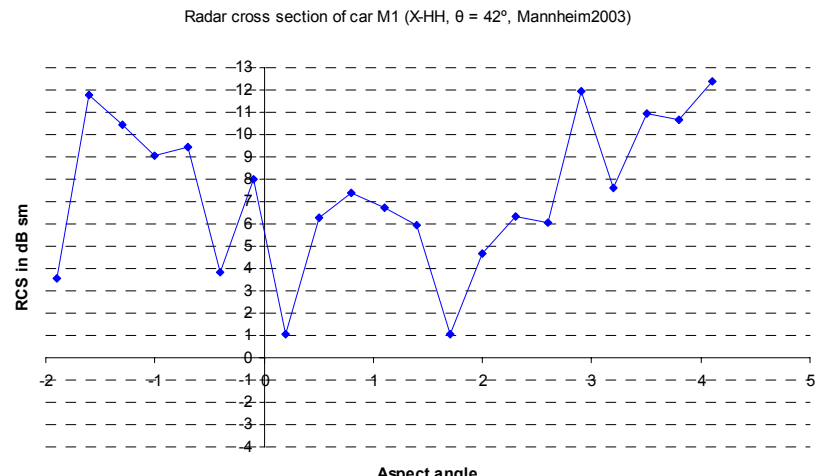

Aspect angle

Figure 6: RCS plot vs. aspect angle for car M1.

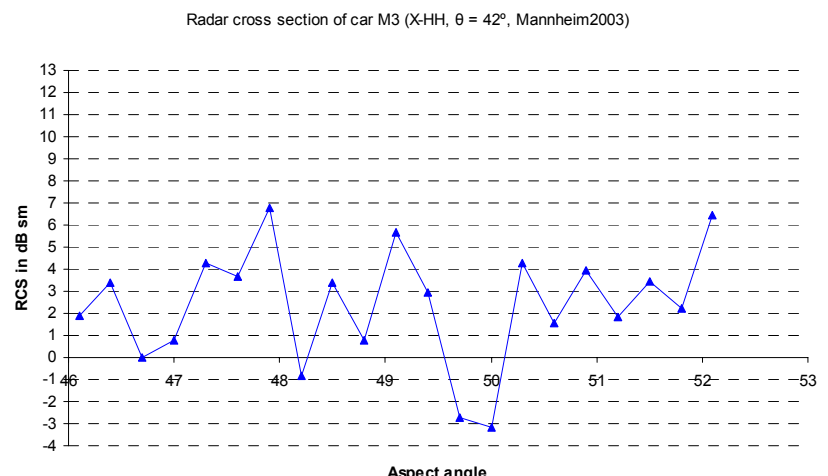

Figure 8: RCS plot vs. aspect angle for car M3.

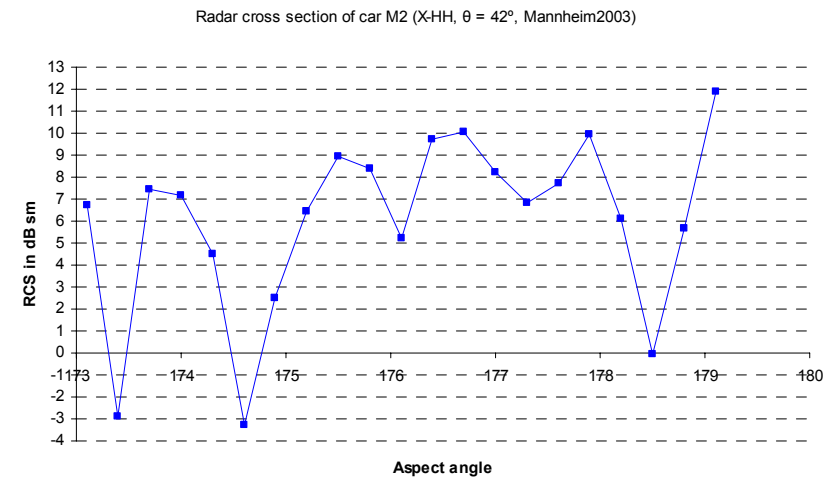

Figure 7: RCS plot vs. aspect angle for car M2.

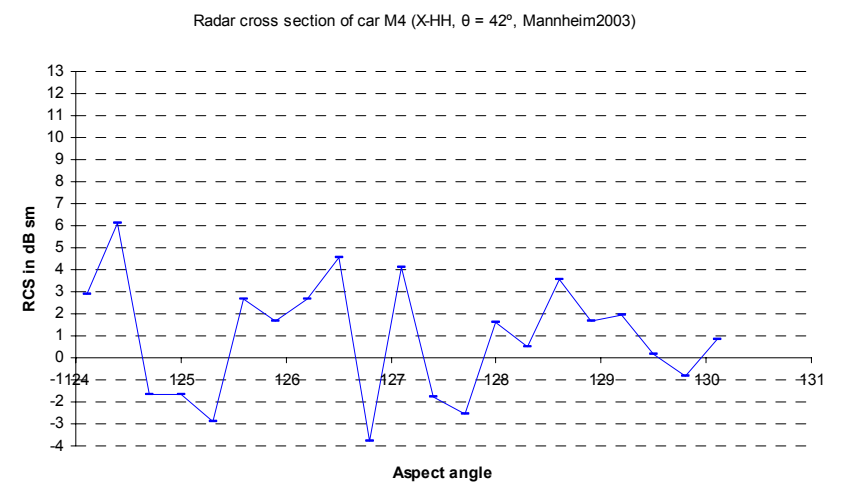

Figure 9: RCS plot vs. aspect angle for car M4.

Table 2: Significance values for Student's T-statistic test.

\begin{tabular}{|l|l|l|l|l|}
\hline Car & M1 & M2 & M3 & M4 \\
\hline M1 & 1.0 & 0.4 & 0.000004 & 0.00000003 \\
\hline M2 & - & 1.0 & 0.0003 & 0.000003 \\
\hline M3 & - & - & 1.0 & 0.08 \\
\hline M4 & - & - & - & 1.0 \\
\hline
\end{tabular}




\subsection{Oberpfaffenhofen flight campaign}

During this flight campaign interferometric (ATI) SAR data were collected with the polarization X-VV. The ground coverage of the data takes are shown in Fig. 10.

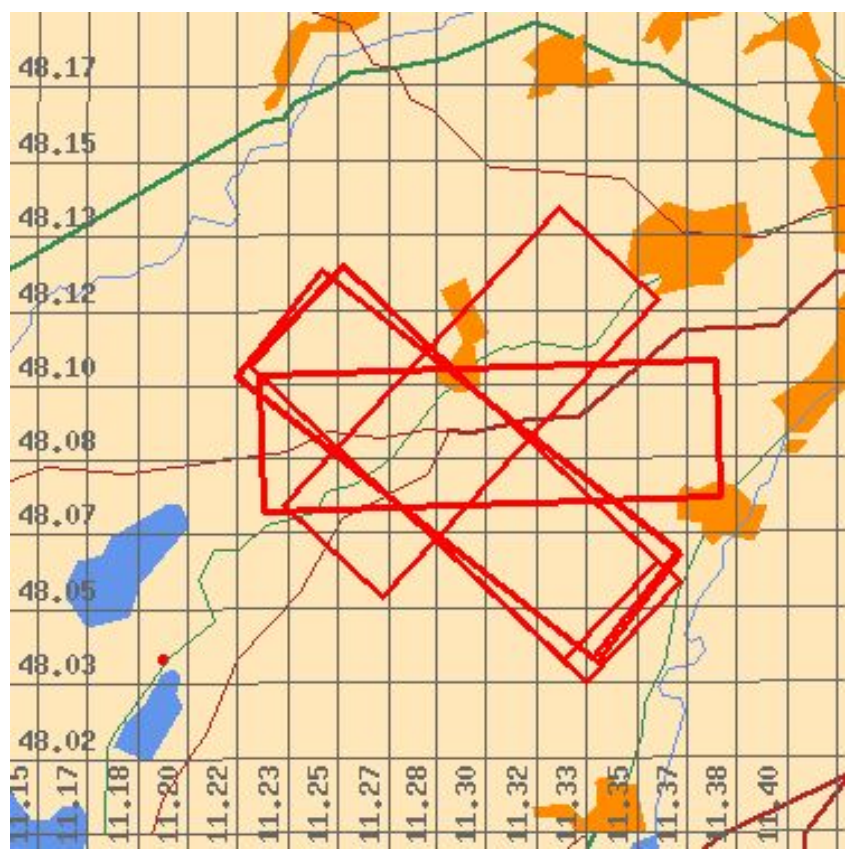

Figure 10: Footprints of SAR data takes for Oberpfaffenhofen campaign.

In parallel to the SAR measurements, again optical data with the RMK large format camera have been acquired. This time the camera was mounted in the same aircraft. Beside parked cars eight moving objects all equipped with GPS receivers covered a speed range from 2 to $90 \mathrm{~km} / \mathrm{h}$. Some results are presented in another paper of this conference $\left(\right.$ Palubinskas ${ }^{14}$ ). In this paper we are concerned only with parking cars. Twenty test cars of different types were placed in parking lots for the validation purposes, see Fig. 11. In the first line are the cars P1C1-P1C6, second - P1C7-P1C12 and third - P2C1-P2C7. These test cars were used to derive the RCS plots vs. aspect angle for X-VV. The incidence angle was approximately $\theta=48^{\circ}$. Figs. 12-14 show the variation of RCS for different types of cars in dependence of aspect angle (for "good" angles). The plots for "bad" angles are not presented here for the lack of the space. Again the statistical test showed that additional RCS variation due different car types does not destroy the significant mean difference between RCS for "good" and "bad" aspect angles.

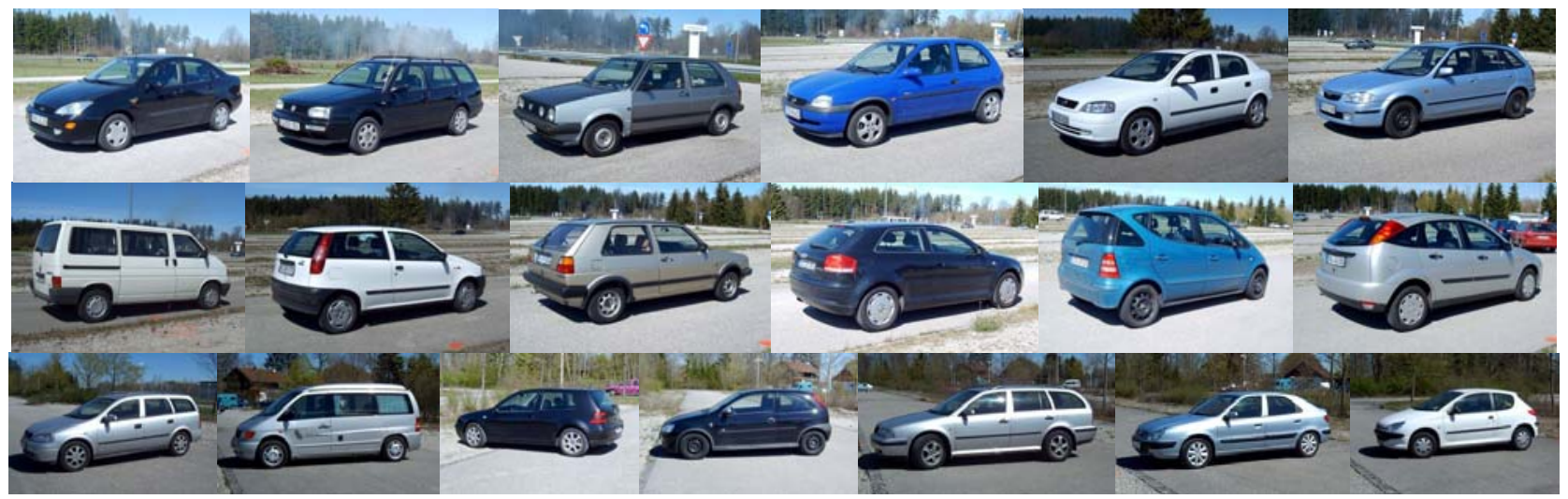

Figure 11: Test cars used for this experiment. 
RCS variation for cars (X-VV, $\theta=48^{\circ}$, OP2004)

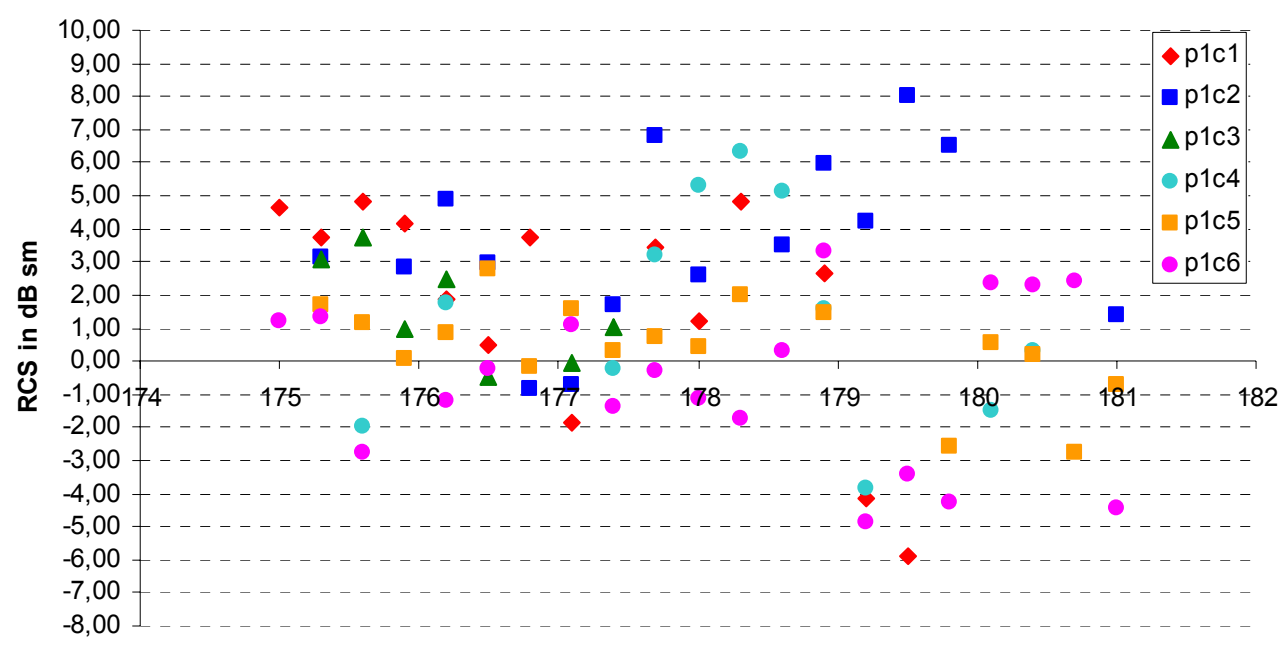

Aspect angle

Figure 12: RCS plot vs. aspect angle for cars (front illumination).

RCS variation for cars (X-VV, $\theta=48^{\circ}$, OP2004)

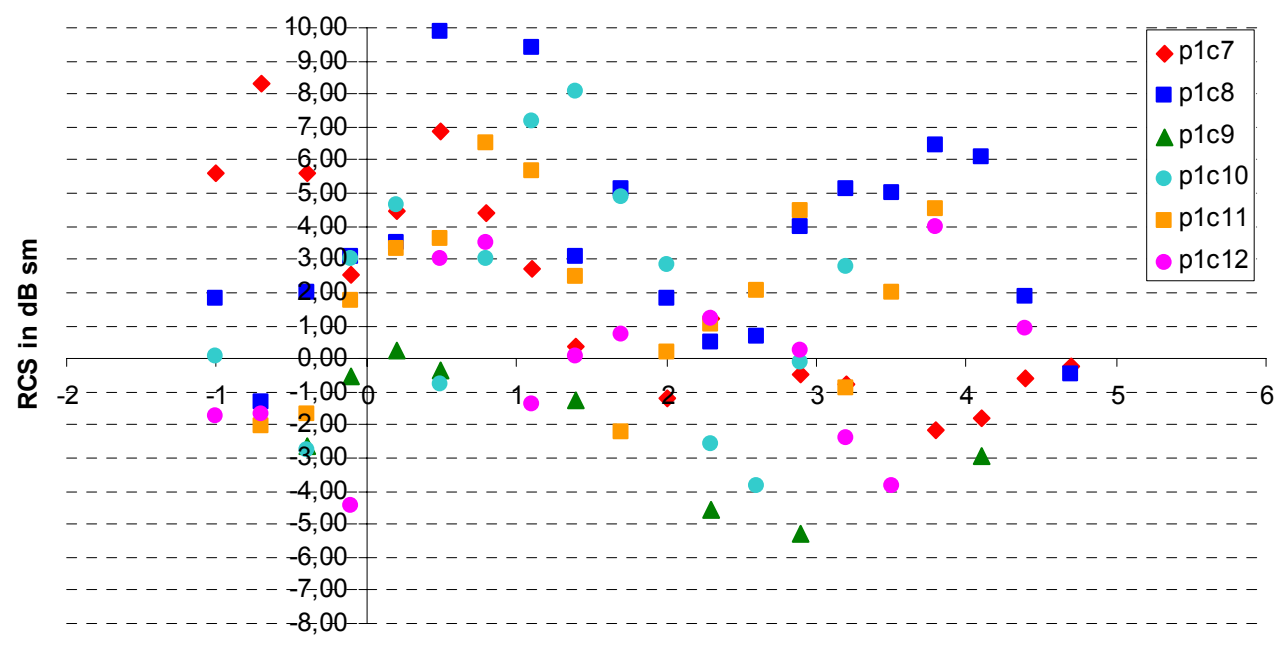

Aspect angle

Figure 13: RCS plot vs. aspect angle for cars (rear illumination). 
RCS variation for cars (X-VV, $\theta=48^{\circ}$, OP2004)

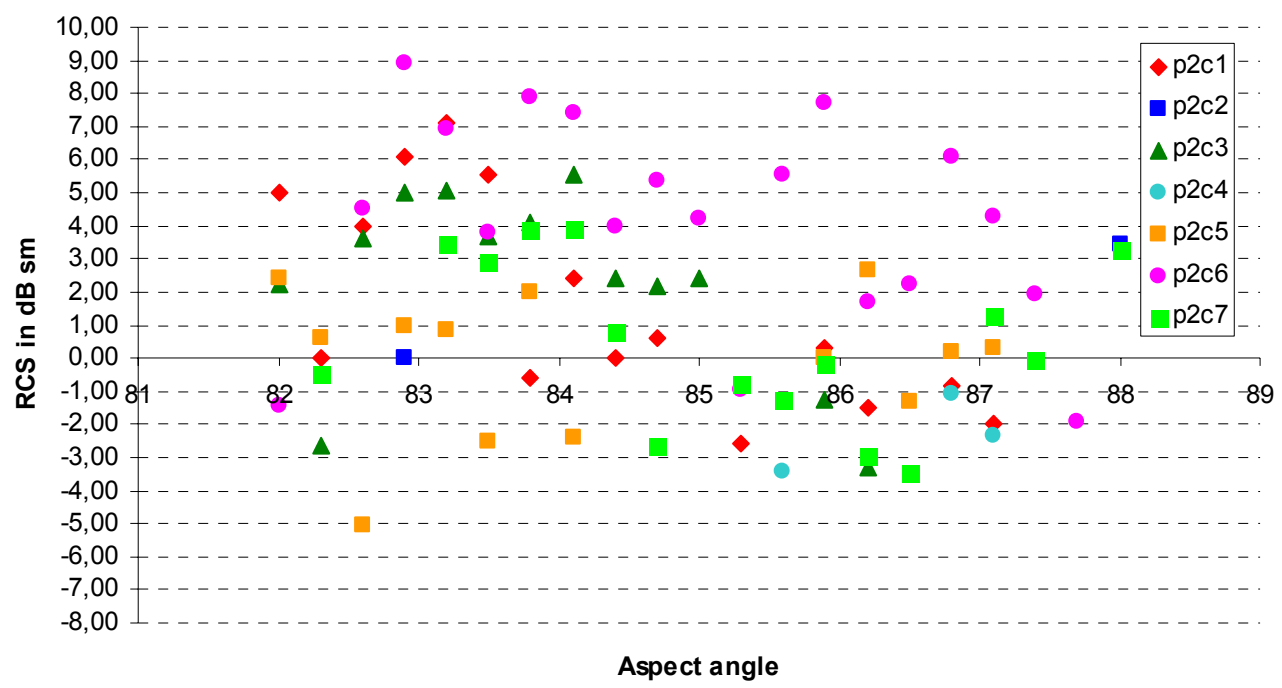

Figure 14: RCS plot vs. aspect angle for cars (side illumination).

\subsection{Gilching flight campaign}

During this flight campaign interferometric (ATI) SAR data were collected for the polarization X-VV. The ground coverage of the data takes are shown in Fig. 15.

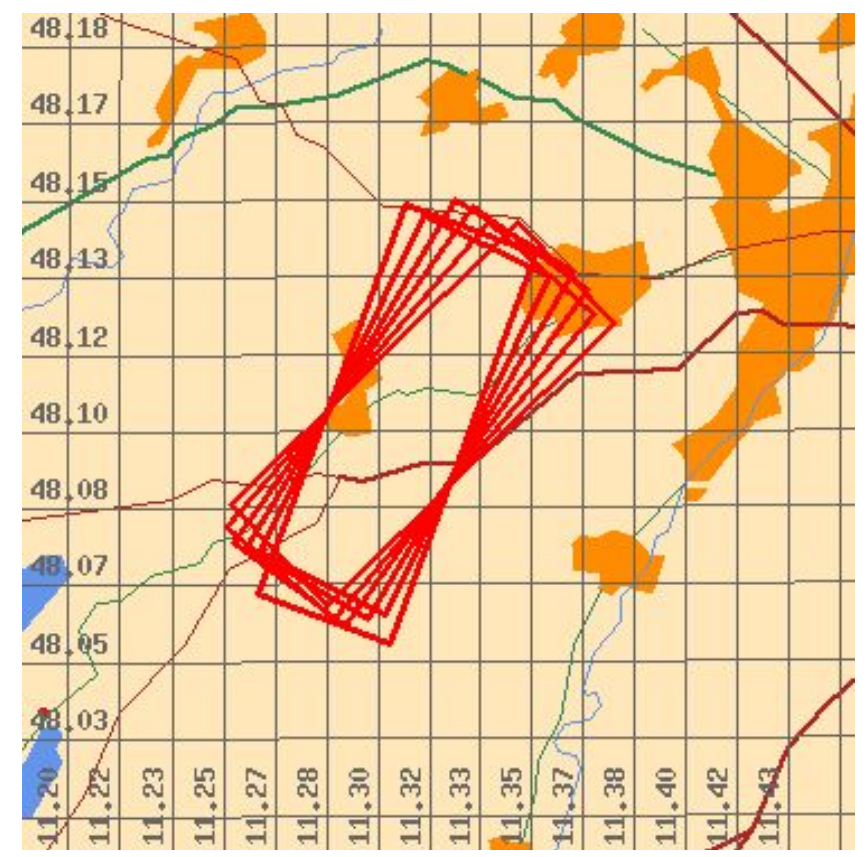

Figure 15: Footprints of SAR data takes for Gilching campaign. 
This flight campaign aimed at the coverage of the whole range of aspect angles by carefully selecting the 6 flight headings (in $5^{\circ}$ step) and placing 7 cars of the same type - VW Golf V - with different orientations (in $30^{\circ}$ step) (see Fig. 16).

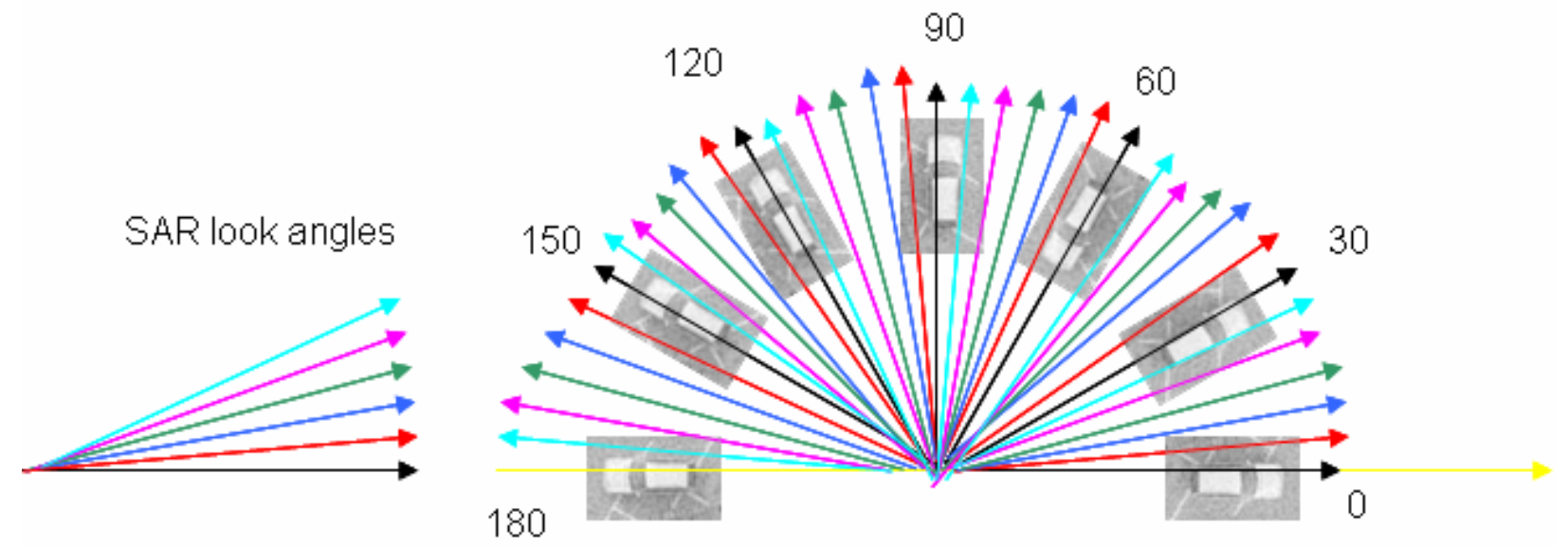

Figure 16: Experiment setup.

In parallel to the SAR measurements, again optical data with the digital camera have been obtained. This time the camera was mounted again in the same aircraft. Derived RCS plot vs. aspect angle for X-VV in one $1^{\circ}$ step is presented in Fig. 17. The incidence angle was approximately $\theta=41.5^{\circ}$. This RCS plot corresponds well with the results of the previous campaigns (compare with Figure 5). Polynomial of the $6^{\text {th }}$ order fits quite well the data. Figs. 18-19 show the overlapping parts of RCS curves in the finest angle resolution of $0.3^{\circ}$.

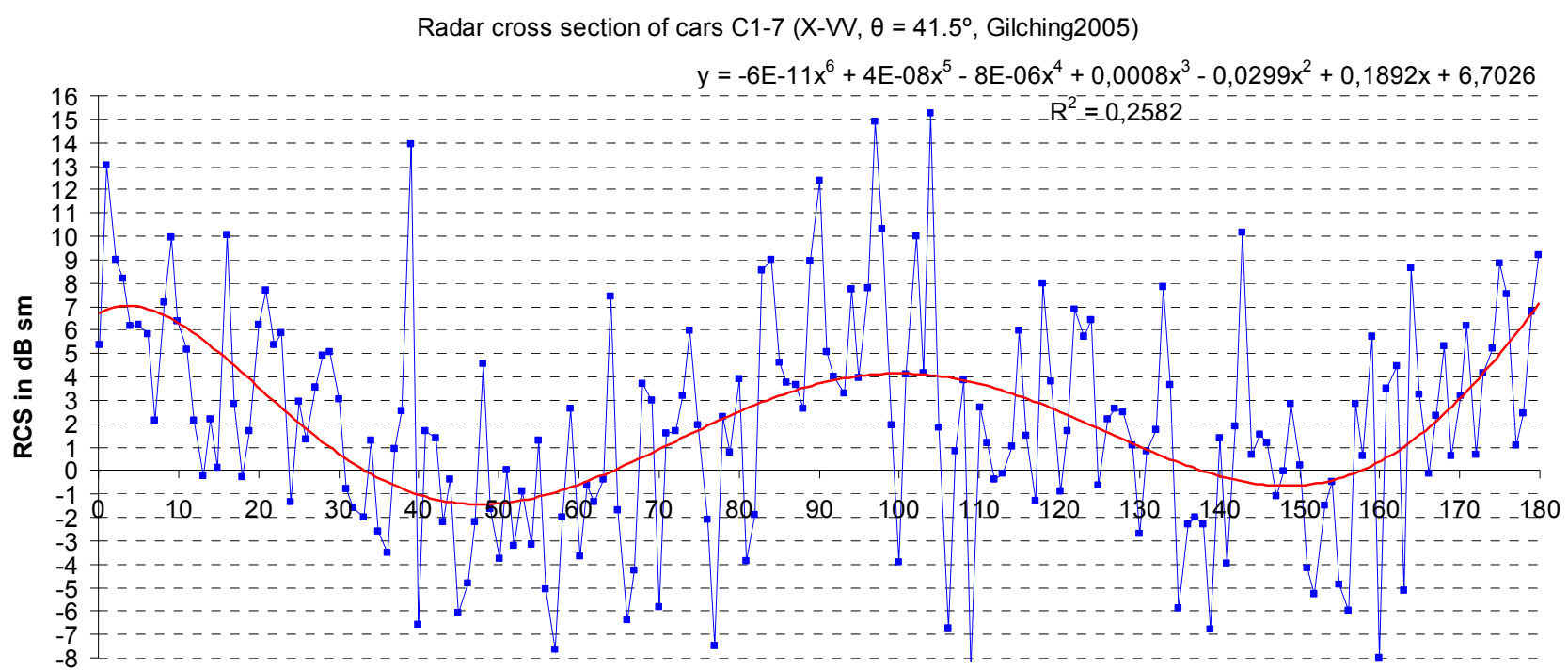

Aspect angle

Figure 17: RCS plot vs. aspect angle for VW Golf V. 


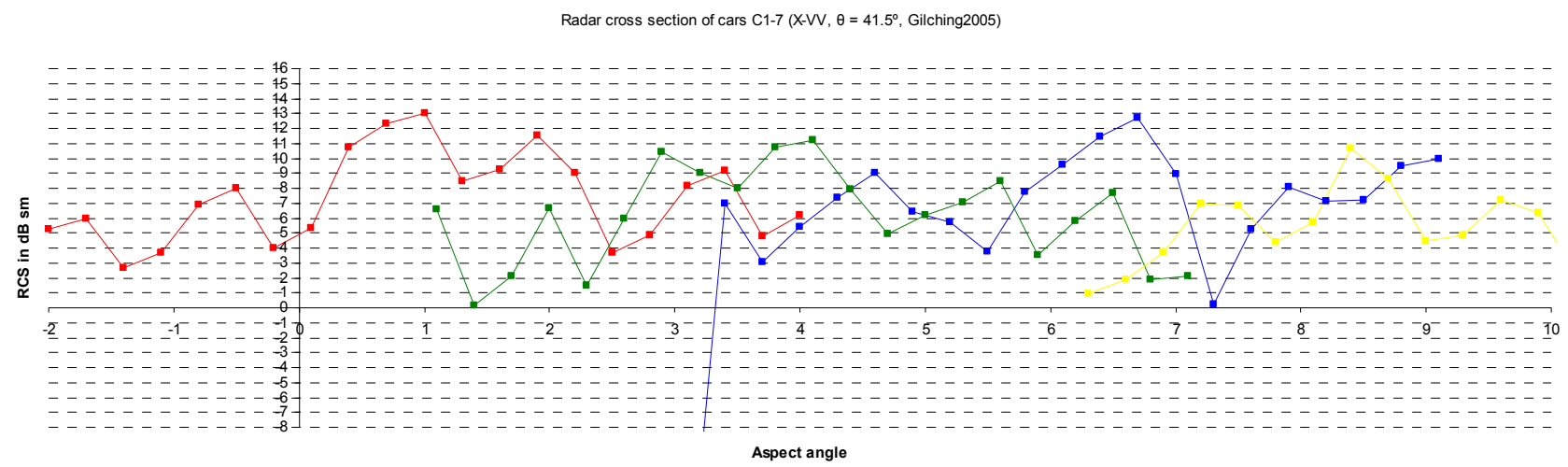

Figure 18: RCS plot vs. aspect angle for VW Golf V (rear view).

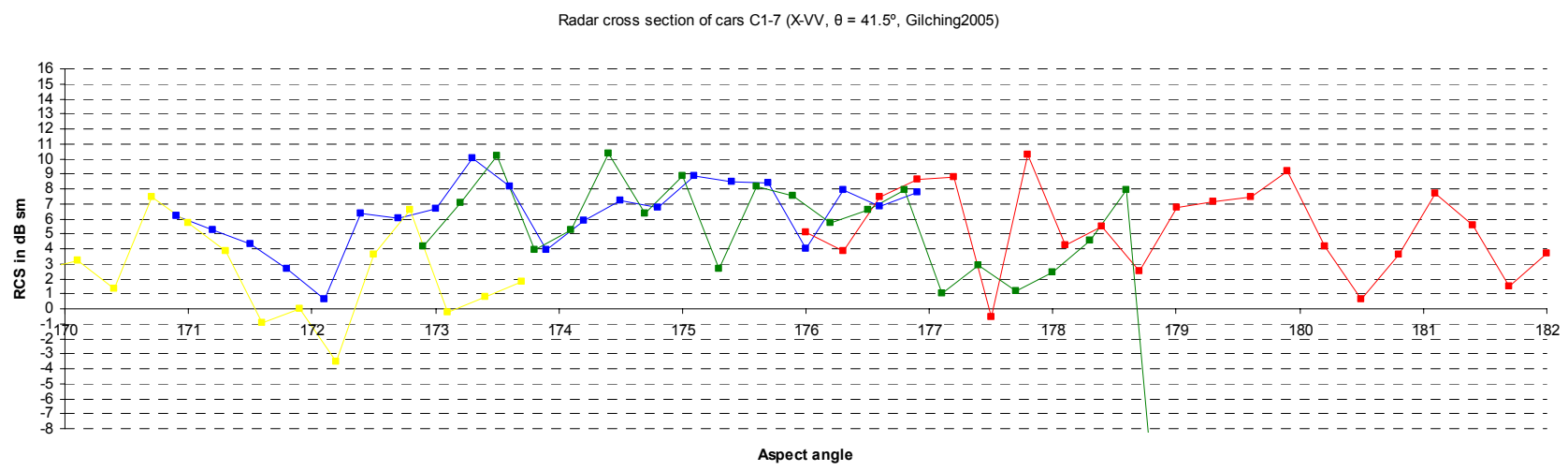

Figure 19: RCS plot vs. aspect angle for VW Golf V (front view).

\section{DISCUSSION}

When analyzing the RCS curves, we find that the cars have quite high RCS values of about $7 \mathrm{~dB} \mathrm{~m}^{2}$, for car aspect angles around $0^{\circ}, 90^{\circ}$ and $180^{\circ}$ which are the so called "good" angles. This result is typical for X-HH and X-VV polarizations. So around these three aspect angles we can expect good car detection. RCS values for the angles around $45^{\circ}$ and $135^{\circ}$ ("bad" angles) mostly are below $0 \mathrm{~dB} \mathrm{~m}^{2}$. These lower values can lead to more difficult detection of the cars. The RCS value of the background (paved road) was about $-20 \mathrm{~dB} \mathrm{~m}^{2}$.

Even three flight campaigns are not enough to cover the full range of parameters on which the RCS depends. For this reason the comparison of experimentally derived RCS with simulated RCS values is planed.

\section{CONCLUSION}

With the three airborne E-SAR flight campaigns the derivation of the catalogue of RCS for road vehicles has been started. This catalogue will serve as a basis for the development of the car detection algorithms, which will be used in the processing of TerraSAR-X data for traffic applications.

\section{ACKOWLEDGEMENTS}

We would like to thank our colleague Helko Breit for theoretical discussions, our trainees: Thomas Galka and Lars Petersen for great help in the visual detection of cars and RCS measurement in SAR image data. The authors would like also to thank Ralf Horn, Rolf Scheiber and Cristopher Laux, all from DLR's Microwave and Radar Institute, for their efforts in planning the campaign flights, data acquisition and SAR data processing. 


\section{REFERENCES}

1. S. Buckreuss, W. Balzer, P. Mühlbauer, R. Werninghaus, and W. Pitz, "The TerraSAR-X Satellite Project," in Proc. of IEEE IGARSS'03 Conference, pp. 3096-3098, 2003.

2. J. Mittermayer, and H. Runge, "Conceptual Studies for Exploiting the TerraSAR-X Dual Receive Antenna," in Proc. of IEEE IGARSS'03 Conference, pp. 2140-2142, 2003.

3. H. Runge, and M. Ruhé, "Verkehrsmonitoring mit dem deutschen Fernerkundungssatelliten TerraSAR-X", DLR Nachrichten 106, pp. 10-15, December 2003.

4. H. Runge, M. Eineder, G. Palubinskas, S. Suchandt, and F. Meyer, "Traffic monitoring with TerraSAR-X", in Proc. of International Radar Symposium (IRS2005), 6-8 September, 2005, Berlin, Germany, 2005. (in print)

5. F. Meyer, and S. Hinz, "The Feasibility of Traffic Monitoring with TerraSAR-X - Analyses and Consequences," in Proc. of IEEE IGARSS’04 Conference, pp. 3096-3098, 2004.

6. S. Suchandt, G. Palubinskas, H. Runge, M. Eineder, F. Meyer, and R. Scheiber, "An airborne SAR experiment for ground moving target identification”, in Proc. of ISPRS Hannover Workshop 2005 - High Resolution Earth Imaging for Geospatial Information, 17-20 May, 2005, Hannover, Germany, ISPRS, vol. XXXVI, part I/W3, 2005.

7. S. Suchandt, G. Palubinskas, R. Scheiber, F. Meyer, H. Runge, P. Reinartz, and R. Horn, "Results from an Airborne SAR GMTI Experiment supporting TSX Traffic Processor Development", in Proc. of IEEE International Geoscience and Remote Sensing Symposium (IGARSS'05), 25-29 July, 2005, Seoul, Korea, IEEE, vol. IV, pp. 29492952, 2005.

8. R.K. Raney, T. Freeman, R.W. Hawkins, and R. Bamler, "A Plea for Radar Brightness," in Proc. of IEEE IGARSS'94 Conference, pp. 1090-1092, 1994.

9. Electronic Warfare and Radar Systems Engineering Handbook, NAWCWPNS TP 8347, 1997.

10. R. Bamler, and B. Schättler, "SAR Data Acquisition and Image Formation," in SAR Geocoding: Data and Systems, G. Schreier, Ed. Karlsruhe: Wichmann, pp. 53-101, 1993.

11. R. Scheiber, A. Reigber, A. Ulbricht, K.P. Papathanassiou, R. Horn, S. Buckreuß, and A. Moreira, "Overview of Interferometric Data Acquisition and Processing Modes of the Experimental Airborne SAR System of DLR", Proc. of IEEE IGARSS'99 Conference, 1999.

12. P. Reinartz, T. Krauss, M. Pötzsch, H. Runge, and S. Zuev, "Traffic Monitoring with serial images from airborne cameras", in Proc. of ISPRS Hannover Workshop 2005 - High Resolution Earth Imaging for Geospatial Information, 17-20 May, 2005, Hannover, Germany, ISPRS, vol. XXXVI, part I/W3, 2005.

13. G. Palubinskas, H. Runge, and P. Reinartz, "Radar signatures of road cars", in Proc. of IEEE International Geoscience and Remote Sensing Symposium (IGARSS'04), 20-24 September, 2004, Anchorage, Alaska, USA, IEEE, vol. II, pp. 1498-1501, 2004.

14. G. Palubinskas, F. Meyer, H. Runge, P. Reinartz, R. Scheiber, and R. Bamler: "Estimation of along-track velocity of road vehicles in SAR data", in Image and Signal Processing for Remote Sensing XI, Lorenzo Bruzzone, Ed., Proc. SPIE, Vol. 5982, 2005.(in press) 